\title{
Degradation of Acetic Acid in Water Using Gas-Liquid Plasma with SPG Membrane*)
}

\author{
Guanyang TANG, Atsushi KOMURO, Kazunori TAKAHASHI and Akira ANDO \\ Department of Electrical Engineering, Tohoku University, Sendai 980-8579, Japan
}

(Received 30 November 2015 / Accepted 9 February 2016)

\begin{abstract}
The gas-liquid mixed phase plasma generated by a nanoseconds-pulsed discharge in bubbles was used for degradation of acetic acid in water. A Shirasu porous glass (SPG) membrane tube was adopted as micro-bubble generator and part of a discharge reactor. A large number of tiny bubbles are generated from dense micro-pores (average diameter of $\phi 50 \mu \mathrm{m}$ ) of the SPG wall and a discharge through SPG membrane was initiated between high voltage electrode and bubble surface. Comparing with a resin tube reactor which has six mechanical holes (diameter of $\phi 1 \mathrm{~mm}$ ), the surface area of bubbles increased with the same gas flow rate. The hydrogen peroxide $\left(\mathrm{H}_{2} \mathrm{O}_{2}\right)$ concentration in treated water using SPG membrane reactor increased by about $71 \%$ compared with that using the resin tube reactor, and the degradation amount of acetic acid was also promoted by about $82 \%$ when Ar gas was used with the flow rate of $2 \mathrm{~L} / \mathrm{min}$. Meanwhile the $\mathrm{H}_{2} \mathrm{O}_{2}$ production and degradation of acetic acid proportionally increased with the growth of gas flow rate in the SPG membrane reactor.
\end{abstract}

(c) 2016 The Japan Society of Plasma Science and Nuclear Fusion Research

Keywords: gas-liquid plasma, degradation of acetic acid, bubbles, SPG membrane

DOI: $10.1585 /$ pfr.11.2406025

\section{Introduction}

Water pollution caused by persistent organic pollutants (POPs) has been one of the serious environmental issues. As one of advanced oxidation processes (AOPs), non-thermal plasma has excellent performance in terms of organic degradation [1]. There have been reported some experiments in degradation of organic pollutant, such as methylene blue for dyeing, phenol for pharmaceutical manufacture. As the advantages of structure and energy efficiency, discharge in bubble and with short pulsed voltage have been applied in some researches [2-6].

In the process of plasma reaction in liquid, various active species such as oxygen radicals $(\cdot \mathrm{O})$, hydroxyl radicals $(\cdot \mathrm{OH})$, and ozone $\left(\mathrm{O}_{3}\right)$ are generated to react with organic pollutants and to initiate degradation processes. Especially, $\mathrm{OH}$ radicals play the key role on the degradation process because of its very high oxidation potential $(2.8 \mathrm{~V})$ which is higher than most of chemical bonding energy in organic pollutants. Therefore, $\mathrm{OH}$ radicals could decompose POPs into $\mathrm{CO}_{2}$ or the other inorganics [7].

In the previous researches we found that the interfacial area of plasma and water was one of the key macroscopic parameters for the generation of $\mathrm{OH}$ radicals, and this was the reason why a bubble discharge had a better performance on degradation of organic than a water surface discharge [8]. When the gas flow rate and reactor volume is fixed due to cost considerations in practical applications, a larger interfacial surface area is feasible and can

author's e-mail: tang@ecei.tohoku.ac.jp

*) This article is based on the presentation at the 25th International Toki Conference (ITC25). be obtained by generating more and smaller bubbles [9].

The SPG (Shirasu Porous Glass) membrane is a kind of new material which has dense holes of uniform micron size $(50 \mathrm{~nm} \sim 50 \mu \mathrm{m})$. These pores are much smaller than those used in the previous gas-liquid mixing devices [10]. Actually, a SPG membrane has already used for the water purification as a micro-bubble generator $[11,12]$. In this research an SPG membrane tube was adopted as bubble generating structure to produce more and smaller bubbles, and it also played as a part of discharge reactor. During the bubbles generation, 360-degrees discharge plasma was initiated. Plasma diffused along the surface of bubbles through the SPG membrane. Through the dependence of $\mathrm{H}_{2} \mathrm{O}_{2}$ generation and organic degradation efficiency on bubble generating structure and gas flow rate, we discussed the advantage of adopting SPG in raising organics degradation efficiency and reducing gas consumption.

\section{Experimental Apparatus and Methods}

A nanosecond pulsed high voltage which is conducive to the non-thermal plasma generation was employed to produce a non-thermal plasma in this organic degradation reactor [13]. The schematic diagram of a pulse highvoltage circuit is shown in Fig. 1. When a charging voltage and pulsed repetition frequency were set to $11 \mathrm{kV}$ and $30 \mathrm{~Hz}$, respectively, a pulsed high voltage (peak voltage $\approx-20 \mathrm{kV}$, pulse width $\approx 40 \mathrm{~ns}$ ) were generated. This kind of nanosecond high-voltage pulse power source was developed in [14]. A $1 \mathrm{k} \Omega$ parallel resistor was used to stabilize 


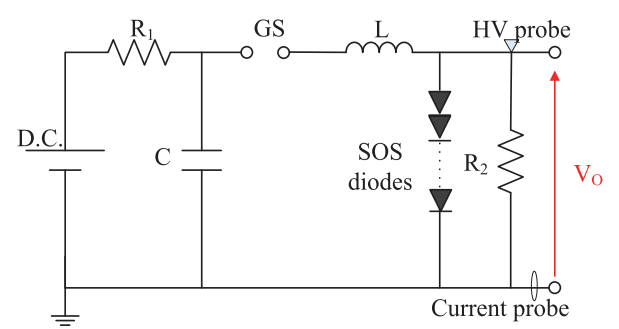

Fig. 1 Schematic diagram of the pulse power supply.

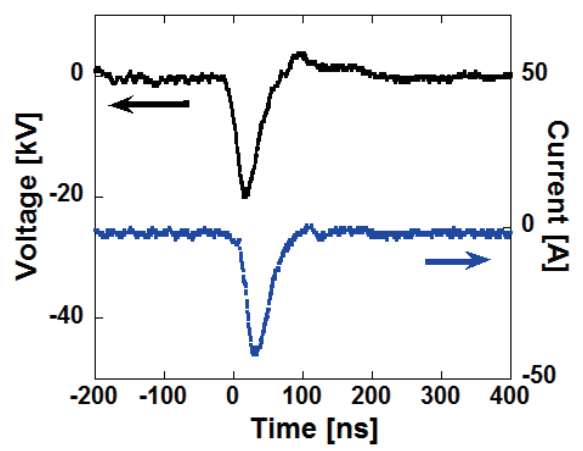

Fig. 2 Typical time evolutions of pulse discharge voltage and current.

the output voltage. Typical temporal evolution of an output voltage and a discharge current are shown in Fig. 2 and it is considered that resistive current is the main component of discharge current.

A Schematic of the gas-liquid mixed phase plasma reactor is shown in Fig. 3. A cylindrical tube, where an SPG membrane or a resin tube is used, is immersed in liquid solution and various species introduced into the tube. A high voltage wire electrode (tungsten wire of $\phi 1 \mathrm{~mm}$ in diameter) placed in its center axis position. A mesh grounded (GND) electrode was immersed in the solution as well. Figures 4 (a) and (b) show an SPG membrane tube and normal resin tube (six holes of $\phi 1 \mathrm{~mm}$ in diameter), respectively. Figure 4 (c) shows a photo of discharge occurred at the six holes in the resin tube. Figure 5 shows a SEM image of the SPG membrane which has porous structure, where each hole diameter is around $\phi 50 \mu \mathrm{m}$. Argon gas was injected into liquid via the holes, and a number of bubbles were formed in the liquid phase. By applying pulsed high voltage, streamer-like discharge was occurred in the tube and also appeared in the bubbles through the holes as shown in Fig. 4 (c).

Acetic acid has a $\mathrm{C}-\mathrm{C}$ bond which has a relatively high binding energy $(2.4 \mathrm{~V})$. This binding energy was higher than the oxidation potential of usual active species in conventional water treatment method such as chlorine or ozone [15]. Then, acetic acid is hardly degradated into inorganics. As $\mathrm{OH}$ radicals has higher oxidation potential, a gas-liquid plasma can be used for the degradation of acetic acid, that is substitute of POPs in this experiment. Acetic acid solution of $100 \mathrm{~mL}$ with the concenration of

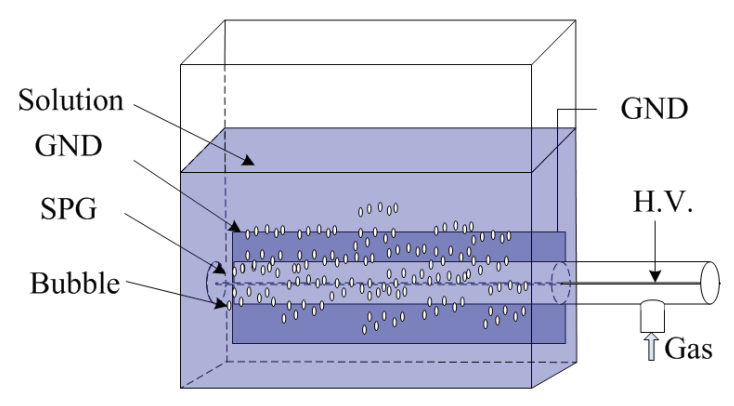

Fig. 3 Schematic of a gas-liquid mixed plasma reactor.

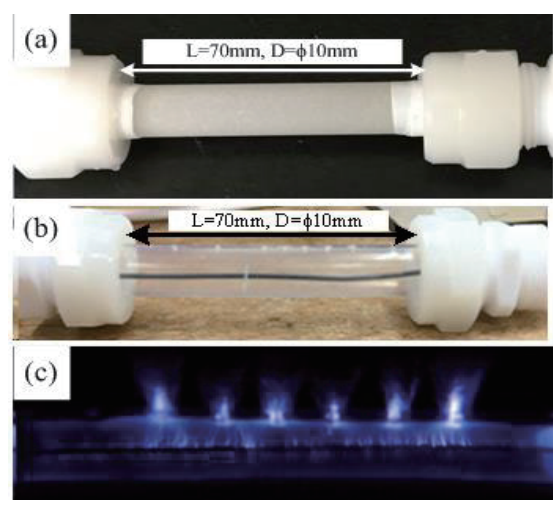

Fig. 4 Photographs of bubble generation structures using (a) an SPG membrane and (b) a resin tube, and (c) a discharge photo taken in the resin tube (exposure time $0.3 \mathrm{~s}$ ).

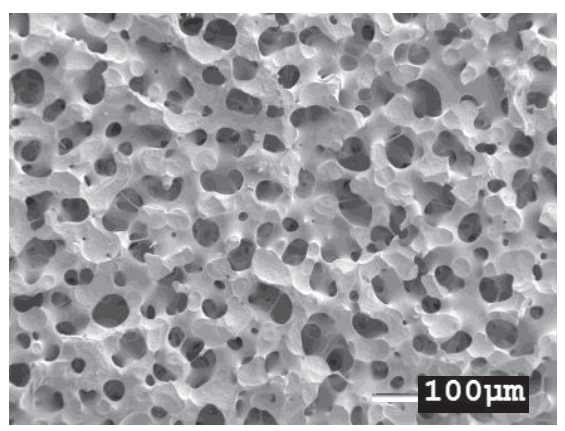

Fig. 5 SEM image of SPG membrane $(\phi 50 \mu \mathrm{m})$ used in this experiment.

$10 \mathrm{mg}_{\text {TOC }} / \mathrm{L}$ was used as the treatment target, the initia conductivity and $\mathrm{pH}$ were about $70 \mu \mathrm{S} / \mathrm{cm}$ and 3.5 , repectivityly. Argon gas was fed to the bubble generating structure with various flow rates.

Due to the extremely short lifetime of $\mathrm{OH}$ radicals in water, the production of $\mathrm{H}_{2} \mathrm{O}_{2}$ was currently used to evaluate the generation of $\mathrm{OH}$ radicals as described in the reaction (1). $\mathrm{H}_{2} \mathrm{O}_{2}$ are widely used as an indicator of $\mathrm{OH}$ radical production because the recombination reaction of $\mathrm{OH}$ radical into $\mathrm{H}_{2} \mathrm{O}_{2}$ is a main quenching reaction [16]. $\mathrm{OH}$ radicals could react with acetic acid and decompose it to $\mathrm{CO}_{2}$ as described in the reaction (2) [17]. We evaluated the degradation effect of acetic acid by the TOC (total organic carbon) measurement. The $\mathrm{H}_{2} \mathrm{O}_{2}$ concentration of the so- 
lution was measured with $\mathrm{H}_{2} \mathrm{O}_{2}$ test kits (Kyoritsu WAK$\mathrm{H}_{2} \mathrm{O}_{2}$ ) and the TOC concentration was measured with TOC analyzer (Shimadazu TOC-L).

$$
\begin{aligned}
\cdot \mathrm{OH}+\cdot \mathrm{OH} & \rightarrow \mathrm{H}_{2} \mathrm{O}_{2}, \\
\mathrm{CH}_{3} \mathrm{COOH}+\cdot \cdot \mathrm{OH} & \rightarrow \mathrm{CH}_{3} \mathrm{CO}_{2}+\mathrm{H}_{2} \mathrm{O} \\
& \rightarrow \mathrm{CO}_{2} \uparrow+\cdot \mathrm{CH}_{3}+\mathrm{H}_{2} \mathrm{O} .
\end{aligned}
$$

\section{Experimental Results and Discus- sion}

When gas was injected to the SPG membrane tube, the surface was covered by tiny bubbles. The number of bubbles decreased with the decrease of gas flow rate $(2 \mathrm{~L} / \mathrm{min}$, $1.5 \mathrm{~L} / \mathrm{min}$ and $1.0 \mathrm{~L} / \mathrm{min}$ ) as shown in Fig. 6. Assuming that bubbles are formed uniformly on the SPG surface and its shape is sphere, about 300 bubbles can be appeared on the SPG surface within a circle of $1 \mathrm{~mm}$ in diameter with $2 \mathrm{~L} / \mathrm{min}$ Ar.

The number of bubbles generated by the SPG membrane tube was estimate by counting bubbles generated on the surface of SPG membrane in the high-speed photography (exposure time $1 \mathrm{~ms}$ ). The equivalent volume of one second was about $30 \mathrm{~mL}$ close to the measured gas flow rate $(33 \mathrm{~mL})$. The gas-liquid interface area almost doubled by using the SPG membrane compared with that by using the resin tube at the same gas flow rate.

The concentration of $\mathrm{H}_{2} \mathrm{O}_{2}$ produced in the solution with the SPG membrane was higher than that with the resin tube in the same discharge frequency $(30 \mathrm{~Hz})$, charging voltage $(11 \mathrm{kV})$ and gas flow rate $(2 \mathrm{~L} / \mathrm{min})$ as shown in Fig. 7. The concentration of TOC was also measured as a function of the treated time as shown in Fig. 8. The $\mathrm{H}_{2} \mathrm{O}_{2}$ production rates, acetic acid degradation rate and acetic acid degradation efficiency were shown in Table 1. It was considered that SPG membrane reactor had a better performance than the resin tube.

The discharge power was calculated by equation (3).

$$
P=\int V \cdot I \mathrm{~d} t \cdot f .
$$

Where $P$ is discharge power (W), $V$ and $I$ are pulsed voltage and current, $f$ is discharge frequency $(\mathrm{Hz})$. Though the output voltage was maintained at about $-20 \mathrm{kV}$, the current (peak value $-40 \mathrm{~A}$ ) in resin tube reactor was larger than that (peak value - 25 A) in SPG membrane reactor. Therefore the discharge power $(0.45 \mathrm{~W})$ of the resin tube reactor was higher than that $(0.38 \mathrm{~W})$ of SPG membrane reactor.

When the gas flowrate was changed, the $\mathrm{H}_{2} \mathrm{O}_{2}$ concentration and TOC concentration were measured as a function of treated time and are shown in Figs. 9 and 10, respectively. These treatment efficiencies are summarized in Table 2. The production of $\mathrm{H}_{2} \mathrm{O}_{2}$, degradation amount and degradation efficiency were approximately in direct proportion to the gas flow rate.

The discharge power did not obviously change with the variation of gas flow rate. As the inside of SPG mem-
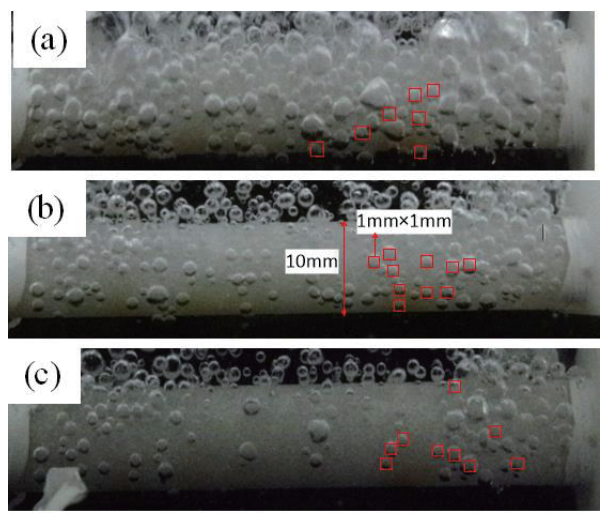

Fig. 6 Photographs of bubble generation using the SPG membrane tube with various gas flow rate. (a) $2 \mathrm{~L} / \mathrm{min}$, (b) $1.5 \mathrm{~L} / \mathrm{min}$ and (c) $1 \mathrm{~L} / \mathrm{min}$.

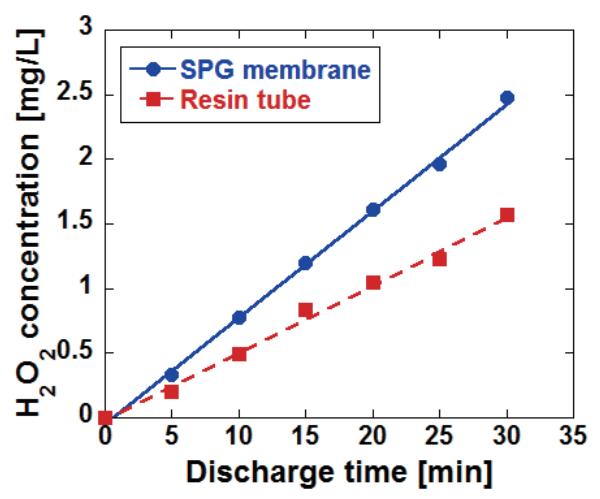

Fig. $7 \mathrm{H}_{2} \mathrm{O}_{2}$ concentration as a function of treated time in the SPG membrane and the resin tube.

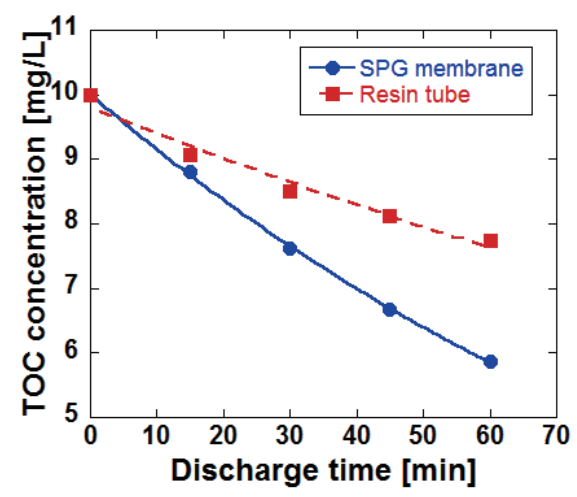

Fig. 8 TOC concentrations of acetic acid solution as a function of treated time in the SPG membrane and resin tube.

brane tube was filled with Ar gas and the outside was water, there was a large relative dielectric permittivity gap between the two phase regions ( 1 in Ar gas and 80 in water). Also the resistance of the solution was low. The high voltage was mainly applied inside of the tube and the discharge type in the SPG membrane reactor was considered to be a wire-cylinder.

DBD discharge. As the electric-field was strong in the vicinity of H.V. wire electrode, electric power was mainly 
Table 1 Numerical results of resin tube reactor and SPG membrane reactor with $2 \mathrm{~L} / \mathrm{min}$ Ar.

\begin{tabular}{l|l|l|l}
\hline & $\begin{array}{l}\mathrm{H}_{2} \mathrm{O}_{2} \text { production rate } \\
(\mu \mathrm{M} / \mathrm{min})\end{array}$ & $\begin{array}{l}\text { Acetic acid degradation } \\
\text { rates }\left(\mu \mathrm{g}_{\mathrm{TOC}} / \mathrm{L} \cdot \mathrm{min}\right)\end{array}$ & $\begin{array}{l}\text { Acetic acid degradation } \\
\text { efficiency }\left(\mathrm{g}_{\mathrm{TOC}} / \mathrm{kW} \cdot \mathrm{h}\right)\end{array}$ \\
\hline Resin tube reactor & 1.4 & 37.8 & 0.5 \\
\hline SPG membrane reactor & 2.4 & 68.9 & 1.1 \\
\hline
\end{tabular}

Table 2 Numerical results of SPG membrane reactor with various Ar flow rates.

\begin{tabular}{l|l|l|l}
\hline $\begin{array}{l}\text { Gas flow rate } \\
(\mathrm{L} / \mathrm{min})\end{array}$ & $\begin{array}{l}\mathrm{H}_{2} \mathrm{O}_{2} \text { production rate } \\
(\mu \mathrm{M} / \mathrm{min})\end{array}$ & $\begin{array}{l}\text { Acetic acid degradation } \\
\text { rates }\left(\mu \mathrm{g}_{\mathrm{TOC}} / \mathrm{L} \cdot \mathrm{min}\right)\end{array}$ & $\begin{array}{l}\text { Acetic acid degradation } \\
\text { efficiency }\left(\mathrm{g}_{\mathrm{TOC}} / \mathrm{kW} \cdot \mathrm{h}\right)\end{array}$ \\
\hline 1.0 & 1.3 & 35.5 & 0.6 \\
\hline 1.5 & 1.9 & 50.7 & 0.9 \\
\hline 2.0 & 2.4 & 68.9 & 1.1 \\
\hline
\end{tabular}

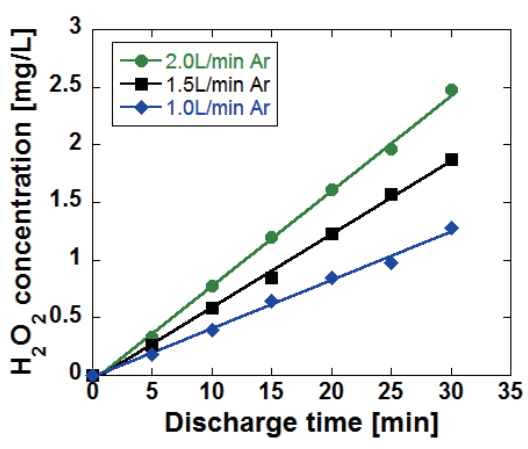

Fig. $9 \mathrm{H}_{2} \mathrm{O}_{2}$ concentration as a function of treated time with various gas flow rate in the SPG reactor.

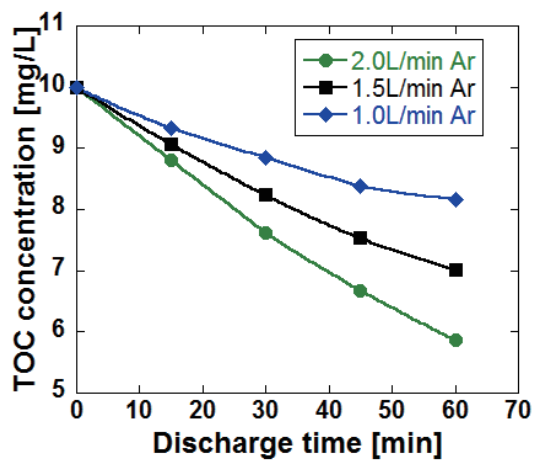

Fig. 10 TOC concentrations of acetic acid solution as a function of treated time with various gas flow rate in the SPG reactor.

consumed here. Plasma was generated near the surface of the wire electrode and expanded toward the wall as a filament-like streamer [18]. A part of plasma streamer diffused into the bubbles via the holes and creeping discharge occurred on the surface of the bubbles. $\mathrm{OH}$ radicals were produced near the interface surface between gas and liquid and degradation reaction of organic was occurred. Therefore, the more bubbles were generated on the surface, the more production of $\mathrm{OH}$ and degradation of POPs were occurred.

\section{Conclusion}

The gas-liquid mixed phase plasma utilizing pulsed high voltage was used for degradation of acetic acid in water. The influence of bubble generating structure and gas flow rate were discussed. By using SPG membrane instead of normal resin tube with $\phi 1 \mathrm{~mm}$ mechanical holes, the gas-liquid interfacial area was enlarged and both $\mathrm{OH}$ radical generation and degradation of acetic acid were enhanced. The productions of $\mathrm{OH}$ radical and degradation amount of acetic acid were approximately proportional to the gas flow rate in the SPG membrane reactor. The degradation efficiency of $1 \mathrm{~L} / \mathrm{min}$ Ar using SPG membrane was almost equal to that of $2 \mathrm{~L} / \mathrm{min}$ Ar with resin tube. The SPG membrane tube worked as an admirable bubble generating structure to provide larger gas-liquid interfacial area in a plasma degradation device. It could effectively improve the organic degradation and reduce gas consumption.

[1] M. Sato et al., IEEE Trans. Ind. Appl. 44, 1397 (2008).

[2] K. Takahashi et al., IEEE Trans. Plasma Sci. 38, 2694 (2010).

[3] K. Sato et al., IEEE Trans. Plasma Sci. 36, 1144 (2008).

[4] K. Takahashi et al., IEEE Trans. Plasma Sci. 39, 2654 (2011).

[5] S. Kawano et al., J. Phys.: Conf. Ser. 441, 012007 (2013).

[6] J. Bo et al., Chem. Eng. J. 236, 348 (2014).

[7] Y. Matsui et al., Plasma Sources Sci. Technol. 20, 034015 (2011).

[8] Y-S. Chen et al., Sep. Purif. Technol. 34, 5 (2004).

[9] X. Wang et al., Nanoscale Res. Lett. 7, 1 (2012).

[10] K. Yasuoka et al., Int. J. Plasma Environ. Sci. Technol. 3, 1 (2009).

[11] T. Tanino et al., J. Inst. Electrostat. Jpn. 34, 31 (2010).

[12] T. Oshima et al., J. Inst. Electrostat. Jpn. 33, 14 (2009).

[13] G. Tang et al., Plasma Fusion Res. 10, 3406022 (2015).

[14] K. Takaki et al., IEEE Trans. Dielectr. Electr. Insul. 18, 1752 (2011).

[15] T. Iijima et al., Toshiba review 61, 40 (2006).

[16] Y. Ishii et al., IEEJ Trans. FM 132, 428 (2011).

[17] F. De Smedt et al., J. Phys. Chem. A 109, 2401 (2005).

[18] F.J.C.M. Beckers et al., IEEE Trans. Plasma Sci. 42, 2404 (2014). 